the non-invasive study of this interesting group of patients.

Basal ganglia calcification has been reported in association with an abnormality of carnitine metabolism ${ }^{6}$ and in two patients with lactic acidaemia and myopathy presumed to be due to disordered mitochondrial metabolism. ${ }^{37}$ It has also been reported in the Kearns-Sayre syndrome $^{8}$ and it is interesting to note that in addition this patient had hypoparathyroidism, an association recorded elsewhere. ${ }^{9}$ We are at present investigating a 42-year-old woman with a suspected mitochondrial disorder who presented with epilepsy, intellectual deterioration, deafness, pigmentary retinopathy, peripheral neuropathy, ataxia and myopathy. She has bilateral basal ganglia calcification, a resting lactic acidosis and ragged-red fibres on muscle biopsy. Preliminary NMR examination has shown no specific abnormality (personal communication, Oxford Clinical Magnetic Resonance Laboratory). Further biochemical studies are being performed.

Apart from myopathy, many other abnormalities have been noted in patients with known or suspected disorders of mitochondrial function. These include various forms of epilepsy, dementia, mental retardation, optic atrophy, pigmentary retinopathy, cataracts, neurosensory deafness, ataxia, peripheral neuropathy, growth retardation and heart conduction defects. The first seven of these were noted either in isolation or in combination in many of the 26 patients reported by Harrington et $a l^{1}$ and it is interesting to speculate whether any of these patients may in fact have an underlying mitochondrial disorder. The apparent absence of myopathy does not preclude this possibility, as it may be very mild or appear as a late manifestation of the disorder. ${ }^{210}$

D HILTON-JONES Dept of Neurology The Radcliffe Infirmary, Oxford $O X 26 H E, U K$

\footnotetext{
References

' Harrington MG, MacPherson P, McIntosh WB, Allam BF, Bone I. The significance of the incidental finding of basal ganglia calcification on computed tomography. J Neurol Neurosurg Psychiatry 1981;44:1168-70.

${ }^{2}$ Morgan-Hughes JA. Defects of the energy pathways of skeletal muscle. In: Matthews WB, Glaser GH, eds. Recent advances in Clinical Neurology 3. Edinburgh: ChurchillLivingstone 1982:1-46.

${ }^{3}$ Skoglund RR. Reversible alexia, mitochondrial
}

myopathy and lactic acidemia. Neurology (Minneap) 1979;29:717-20.

4 Swash M, Schwartz MS, Sargeant MK. The significance of ragged-red fibres in neuromuscular disease. J Neurol Sci 1978;38: 347-55.

${ }^{5}$ Hoult DI, Busby SJW, Gadian DG, Radda GK, Richards RE, Seeley PJ. Observation of tissue metabolites using ${ }^{31} \mathrm{P}$ nuclear magnetic resonance. Nature 1974;252:285-7.

- Smyth DPL, Lake BD, MacDermot J, Wilson J. Inborn error of carnitine metabolism ("carnitine deficiency") in man. Lancet 1975; i: $1198-9$.

' Markesbery WR. Lactic acidemia, mitochondrial myopathy and basal ganglia calcification. Neurology (Minneap) 1979;29:1057-61.

${ }^{8}$ Pellock JM, Behrens M, Lewis L, Holub D, Carter S, Rowland LP. Kearns-Sayre syndrome and hypoparathyroidism. Ann Neurol 1978;3:455-8.

9 Horwitz SJ, Roessmann U. Kearns-Sayre syndrome with hypoparathyroidism. Ann Neurol 1978;3:513-8.

${ }^{10}$ Olson W, Engel WK, Walsh GO, Einaugler R. Oculocraniostomatic neuromuscular disease with "Ragged-Red" fibers. Arch Neurol 1972;26:193-211.

\section{Reply letter}

Sir: We are interested in the points Dr Hilton-Jones makes concerning disorders with mitochondrial abnormalities and clearly these would be added to our list of conditions associated with basal ganglia calcification. The associated clinical abnormalities in patients with mitochondrial disorders were often found in our own patient group but many were also present in our control group. While the apparent absence of myopathy does not exclude mitochondrial disorder, it is significant that none of our patients had any clinical suggestion of muscle weakness or ophthalmoplegia. We cannot provide more factual information because we did not study mitochondrial antibodies or muscle histology in either our patient or control group.

From our original study we felt that the main practical value of radiographic basal ganglia calcification was as an indicator or treatable parathyroid disease that had not come to attention previously. We have identified a further ten patients incidentally and chose to review them clinically because the two identified during our study were recognisable with hindsight on clinical grounds to have parathyroid disease. One patient had all the features of idiopathic hypoparathyroidism; this was confirmed biochemically and she is now on specific therapy. This suggests an important principle for the incidental basal ganglia calcification found on computed tomography: all patients should be reviewed clinically with regard to parathyroid diseases and in this way a steady trickle of treatable disease will be picked up, much as happens from following up incidental abnormalities of blood calcium in hospital patients. Three cases out of 36 in our population are a worthwhile reward, but clearly these numbers are too small to generalise.

MG HARRINGTON

P MACPHERSON

WB MACKINTOSH

BF ALLAM

I BONE

Southern General Hospital

1345 Govan St

Glasgow G51 4TF, UK

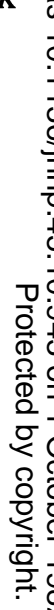

